\title{
TPX POLOIDAL FIELD (PF) POWER SYSTEMS SIMULATION
}

\author{
E. Lu, G. Bronner (Princeton Plasma Physics Laboratory, Princeton, NJ), \\ C. Neumeyer (Ebasco Services, Inc., NY, NY)
}

\section{ABSTRACT}

This paper describes the modeling and simulation of the PF power system for the Tokamak Physics Experiment (TPX), which is required to supply pulsed DC current to the Poloidal Field (PF) superconducting coil system. An analytical model was developed to simulate the dynamics of the PF power system for any PF current scenario and thereby provide the basis for selection of PF circuit topology, in support of the major design goal of optimizing the use of the existing Tokamak Fusion Test Reactor (TFTR) facilities at the Princeton Plasma Physics Lab (PPPL).

\section{INTRODUCTION}

The simulation method [1] takes into account the concepts and features of the proposed circuit scheme [2], in which each of the independent PF circuits will be controllable via series/parallel combination of existing phase controlled thyristor converters to produce a unique pulse current waveform. The converters will be fed from one of the two existing TFTR Motor-Generator (MG) sets with adjustable voltage via excitation control. In modeling the anti-parallel connected converter circuits which convert $A C$ power to $D C$ output power under bi-directional and regular/bypass operation, careful consideration is given to accommodate the different patterns of conduction. Thermal constraints are of major concern with respect to the anticipated "long bum" mode of TPX operation.

Simulations involve: 1) Determining the mutual inductance matrix and resistance vector of the coupled EM circuits; 2) Interpolating the reference waveforms from the tabular PF scenario; 3) Determing the power supply voltages and operating modes as demanded by the current waveforms and a chosen circuit topology, incorporating the requirements imposed by coil current polarity; 4) Evaluating the required Motor-Generator system power, energy and frequency, etc.; 5) Generating current profiles of $I_{\text {ave }} \& I_{r m s}$ in major power system components and simulating their transient thermal behavior.

The derived computer algorithm does not simulate the detailed electrical behavior of all phases of the power-system since the focus is centered on gaining insight into the system requirements and providing adequate information for cinosing a PF circuit topology guided by limiting criteria. Some technical background \& programming considerations in the development of the simulation model are described in the following paragraphs. Finally, it is noted that startup and energy dump issues, which require special case studies are not covered under the scope of the work described here.

Manuscript received October 14, 1993. This work was supported by U.S.Department of Energy Contract No. DE-AC02-76-CHO3073.

\section{TECHNICAL BACKGROUND AND PROGRAMMING CONSIDERATIONS}

\section{Coupled EM Circuits}

The PF coils, the plasma current, as well as the passive structures (vacuum vessel, passive stabilizer, etc.), constitute coupled EM circuits in a tokamak. In the subject work, the plasma current was modeled as a single filament placed at the current centroid rather than the plasma center. Parameters of the plasma are assumed to be fixed throughout the calculation. The vacuum vessel is modeled as loop-segments coaxial with the PF coils. As a matter of programming convenience, other secondary current paths such as the passive stabilizer, are neglected at present because passive structures make a negligible contribution to PF coil circuits in situations involving slow field changes but increase the computational burden for long-pulse simulations.

\section{Load Representation}

The PF current profiles are specified as tabular scenarios, so that a linear interpolation process is used to calculate the value of current and its derivatives at any arbitrary point in time. The PF current profiles drive several interacting effects: they set the circuit voltage which determines the power supply voltage; they drive conductor power loss and thus raise the temperatures and resistances of the components; they drive the total power loss in the system and thus the removal of energy from the generator, causing it to slow down and produce AC output at a lower frequency.

\section{Coil Terminal Voltage}

The coil terminal voltage is obtained via the solution of the linear differential equations governing the dynamics of $N_{\rho p}+N_{p s}+N_{w}$ coupled circuits. Putting this into compact vector notation yields the relationship

$$
\begin{aligned}
& \left.\left[V_{P F}\right]=\left[L_{P F} \mathbf{I} \frac{d J_{P F}}{d t}\right]+\left[L_{P F, P L S} \mathbf{I} \frac{d J_{P L S}}{d t}\right]+\left[L_{P F, W}\right) \frac{d J_{W}}{d t}\right] \\
& \left.\left[V_{P L S}\right]=\left[L_{P F, P L}\right) \frac{d I_{P F}}{d l}\right]+\left[R_{P L S}\right)\left(I_{P L S}\right]+\left[L_{P L S}\right)\left(\frac{d J_{P L S}}{d l}\right]+\left[L_{P L S, W}\right)\left(\frac{d I_{W V}}{d l}\right] \\
& {\left[V_{w}\right]=\left[L_{p F, w}\right)\left[\frac{d I_{p F}}{d t}\right]+\left[L_{p L S, w}\right)\left(\frac{d I_{p L s}}{d t}\right]+\left[R_{v V}\right)\left[I_{v v}\right]+\left[L_{w V}\right)\left(\frac{d I_{w V}}{d t}\right]}
\end{aligned}
$$

where PF represents the PF coils, PLS the plasma, and VV the vacuum vessel. It has been assumed that superconducting coils are used $\Rightarrow\left[R_{p p}\right]=[0]$. Since the plasma and vacuum vessel are passively driven by the $P F$ currents, $\left[V_{p c s}\right]=\left[V_{w}\right]=[0]$. The following steps are required to obtain the solution: 
1. Summing up all known terms in the third equation of $(1)$ as $\left[V_{w}{ }^{\prime}\right]$, which gives the first-order differential equation

$$
\left[R_{v v}\right]\left[I_{w}\right]+\left[L_{v v}\right]\left[\frac{d I_{w v}}{d t}\right]=\left[V_{w}{ }^{\prime}\right]
$$

2. Solving (2) with zero-initial conditions.

3. Determining the coil voltage $\left[V_{P F}\right]$ from the first equation of (1).

In the long-pulse operation, the electrical load characteristics of the superconducting TPX machine leads to reduced coil voltage requirements by nearly a factor of 100 from the plasma ramping mode to the flat top mode. The simulation provides the capability for a variable $\mathrm{AC}$ input voltage to the rectifier converters, which is desirable to improve the power factor and reduce the hamonic content of the converter output voltage during the plasma burn.

\section{PF Circuit}

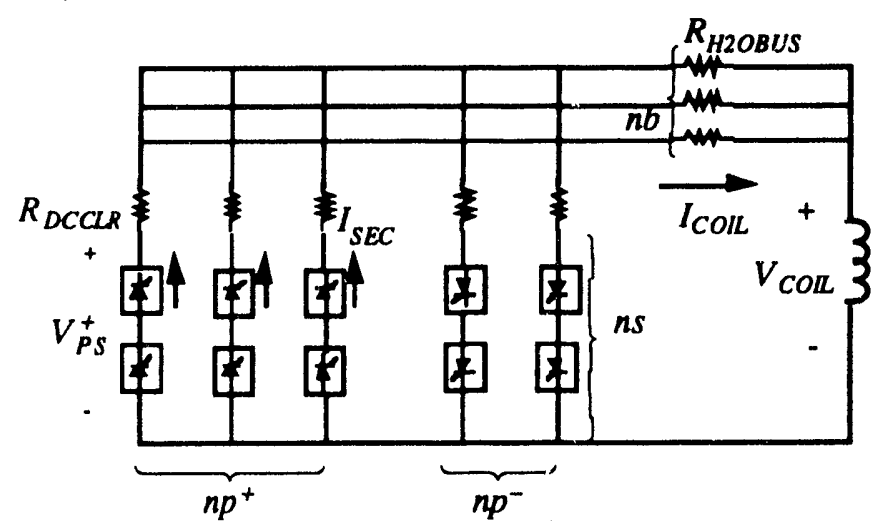

Fig. 1 A Typical PF Circuit Model

A typical PF circuit will function as a 4-quadrant AC/DC converter. The simplified configuration is schematically represented in Fig. 1, where $V_{p s}$, the voltage demand from d.c. power supplies each with $n s$ rectifier section in series, is an external controllable voltage applied to the PF circuit. Two groups, each with individual $n p$ branches in parallel, of power supplies are connected in the opposite direction to conduct bipolar current; the symbols "+" and "-" are associated with the load current direction with the polarity shown. The current limiting reactor in series with each parallel branch is modeled as a single lumped resistor $R_{\text {ocCse }}$; the $R_{\text {Hzoses }}$ is the resistance of the water cooled bus.

The basic rectifier converter model is a 6-pulse bridge converter with a freewheel thyristor connected directly across its d-c terminals. Each rectifier consists of a number of thyristors connected in series and parallel as shown in Fig. 2. The Power Module (PM) rectifier consists of an assembly of 6 modules connected in parallel, each with 4 thyristors in series; the Bypass Module (BM) rectifier consists of an assembly of 12 modules connected in parallel, each with 2 thyristors in series. Factors are included in the computation to account for the imbalance in current flow amongst the parallel paths.

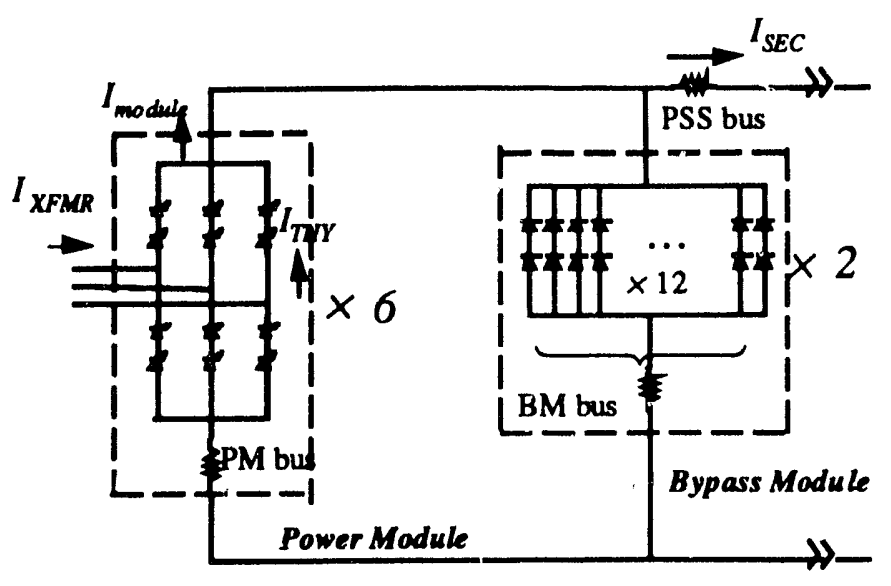

Fig. 2 Basic Rectifier Converter Model

\section{a. Single Rectifier Converter Simulation}

The simulation of the behavior of a rectifier at any desired load conditions is realized by a simplified model. This model does not compute the instantaneous values of the voltage that is applied to the coils, but instead computes the average dc output voltage from a rectifier. The following relationship describes the model:

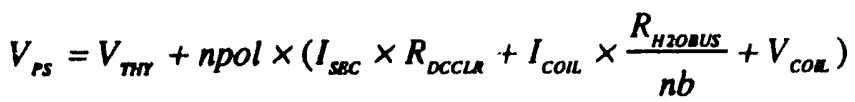

where, $V_{n r y}$ is the total forward voltage drop of thyristors in one branch, computed based upon their on-state characteristic and average thyristor currents. Since the voltage drop is significant in comparison with the desired coil voltage during the plasma burn phase, it can not be neglected. A comprehensive approach to solution requires that tie current be determined beforehand. Since the detailed current distribution is not known (a priori), an average current value is used instead. The same method applies to determine the operating mode of the rectifier. Referring to Fig. 1, $I_{S B C}$ is the $\mathrm{PF}$ current divided among $n p$ parallel paths, and $n p o l$ is the polarity index.

The model determines the operating mode of the rectifier in terms of the dc voltage ratio $r\left(=V_{d \alpha} / V_{d o}\right) . V_{d \alpha}$ is the average direct voltage at firing angle $\alpha$ and equal to the sum of the rectifier section voltage $\left(V_{S E C}=V_{P S} / n s\right)$ and the average commutating voltage loss. $V_{d o}$ is the average direct voltage that could be attained at no load with zero phase control . The model determines operating mode from each rectifier as follows: when the dc ratio falls into "range $0 \leq r<0.5^{\prime \prime}$, the rectifiers are put into a bypass operation mode; the rectifiers are driven into inversion at the instant the dc voltage ratio becomes negative. The model updates the rectifier-operating status every time step.

\section{b. Criteria for Optimization of PF Circuit Topology}


The objective of the topology optimization is to maximize the utilization of existing TFTR facilities. The determination of PF circuit topology is subject to topological constraints as follows: the number of series ( $n s$ ) connected rectifier sections in each parallel/anti-parallel, must be equal and even numbers in order to accommodate the Single-Null (SN) plasma operation. The number of parallel $(n p)$ connected rectifier sections and the number of parallel $(n b)$ water-cooled buses are determined by device current rating.

To provide ample safety factor for thyristors, the voltage margin is defined as follows:

$$
\begin{aligned}
& V_{\max }^{+}=V_{d o}-V_{x} \quad<-- \text { converter } \\
& V_{\max }^{-}=0.6 \times V_{d o} \quad<--- \text { inverter } \\
& V_{x_{0}}=\left(1-\left|V_{S E C}\right|_{V_{\max }}\right) \times 100 .
\end{aligned}
$$

where, $V_{\max }$ is the maximum voltage that could be attained by all of the rectifiers that are active at the moment, $V_{d o}$ the theoretical direct voltage with zero phase control @ no-load, and $V_{x}$ the commutating voltage drop due to the AC system inductance. The required minimum voltage margin is $10 \%$.

\section{Energy Supply}

In estimating the energy supply and losses in the PF power supply ald distribution system, the complexity of a composite AC/DC model is eliminated by some simplifications. The parameters of the AC power system, which consists of the existing TFTR motor generator (MG) sets, AC feeder lines including current limiting reactors and transformers, are referred to the $\mathrm{DC}$ side. The $\mathrm{MG}$ is represented as programmable source of voltage $\left(E_{s}\right)$ behind a fixed reactance.

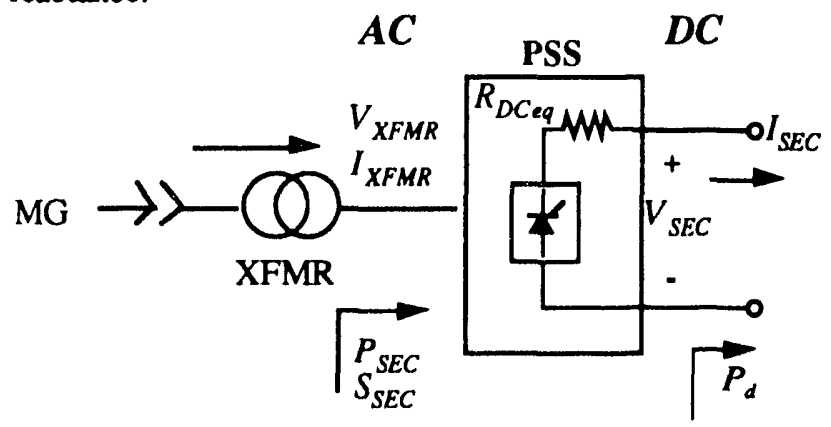

Fig. 3 The Flow of Rectifier Section Power

This model computes the dc load power and the ac power and the apparent power of each rectifier section; then adds them together and computes the total amount of power drawn from the generator. Fig. 3 shows how the model simulates the flow of section power. It computes 1$)$ the effective power as $P_{S E C}=V_{S E C} \times I_{S E C}+I_{S E C}^{2} \times R_{D C \text { eq }}$, where $V_{S E C} \times I_{S E C}$ is the effective power delivered to the dc terminal and $I_{S E C}^{2} \times R_{D C \text { eq }}$ the AC feeder loss power; 2) the apparent power as $S_{S E C}=3 \times V_{X F M R, L N} \times I_{X F M R}$, where $V_{X F M R, L N}$ and $I_{X F M R}$ are rms values of transformer secondary L-N voltage and current respectively. It then evaluates the energy in terms of the integration of power by the trapezoidal rule; and, furthermore, computes the total energy drawn from the generator, decrements of the generator flywheel energy, and the frequency.

The control strategy of the motor is incorporated into the simulation depending on the need for the extra PF energy via the TFTR MG sets. It starts at zero input power. Once the frequency goes out of pre-specified limits, the motor is then turned on and powered at a pre-set level to cover the energy shortfall.

\section{Transient Thermal Analysis}

For "long-burn" operating cycles, with a 1000 second plasma burn pulse repeated once every 4500 seconds, a major issue is the temperature of electrical components. Therefore, examination of the thermal responce of major electrical components is necessary.

Fig. 4 shows a basic thermal model with a cascade $R-C$ circuit, where $P$ is the input power (watts), $T$ temperature $\left({ }^{\circ} C\right), R$ thermal resistance, $C$ thermal capacitance, $T_{a m b}$ ambient temperature, and $n$ number of $R-C$ stage. The simulation algorithms and detailed models, including MG winding temperature, bus temperature, rectifier transformer winding temperature and thyristor junction temperature, are described in [3]. Inputs to this section are current profiles of $I_{\text {ave }} \& I_{r m s}$, from which the power losses are determined as $P=P_{\text {cosf } 1} \times I_{\text {ave }}+P_{\text {coeff } 2} \times I_{\text {ms }}^{2}$ for transient thermal

\begin{tabular}{|c|c|c|}
\hline Component & Regular Mode & Bypass Mode \\
\hline $\mathrm{H}_{2} \mathrm{O}$ bus & $I_{r m s}=I_{\text {coil }} / n b$ & - \\
\hline$P M$ thyristor & $\begin{array}{l}I_{\text {module }}=\frac{1.2}{6} \times\left|I_{\text {rec }}\right| \\
I_{\text {ave }}=I_{\text {module }} / 3 \\
I_{\text {rms }}=\sqrt{1 / 3} \times I_{\text {module }}\end{array}$ & $\begin{array}{l}I_{\text {ave }}=\frac{\delta}{\pi} \times I_{\text {module }} \\
I_{\text {rms }}=\sqrt{\frac{\delta}{\pi}} \times I_{\text {module }}\end{array}$ \\
\hline$P M$ bus & $I_{\text {rms }}=I_{\text {module }}$ & $I_{\text {rms }}=\sqrt{\frac{\delta}{\pi / 3}} \times I_{\text {module }}$ \\
\hline$B M$ thyristor & $I_{\text {ave }}=I_{r m s}=0$ & $\begin{array}{l}I_{\text {branch }}=\frac{1.2}{12} \times\left|I_{\text {soc }}\right| \\
I_{\text {ave }}=\frac{\pi / 3-\delta}{\pi / 3} \times I_{\text {branch }} \\
I_{\text {rms }}=\sqrt{\frac{\pi / 3-\delta}{\pi / 3}} \times I_{\text {branch }}\end{array}$ \\
\hline$B M$ bus & $I_{r m s}=0$ & $\begin{array}{l}I_{\text {module }}=\left|I_{\text {sec }}\right| / 2 \\
I_{\text {rms }}=\sqrt{\frac{\pi / 3-\delta}{\pi / 3}} \times I_{\text {module }}\end{array}$ \\
\hline PSS bus & $I_{\text {rms }}=I_{s o c}$ & - \\
\hline $\begin{array}{l}P S \\
\text { transformer }\end{array}$ & $I_{m s}=\sqrt{\frac{2}{3}} \times I_{\mathrm{sec}}$ & $I_{\text {rms }}=\sqrt{\frac{\delta}{\pi / 2}} \times I_{s e c}$ \\
\hline
\end{tabular}
analysis. A summary is given here [1]:

1. Currents in a Rectifier System (referring to Fig. 1-2):

* $\delta$ is the conduction angle and "1.2" the safety coefficient. 


\section{MG Currents:}

\begin{tabular}{|l|l|}
\hline Stator & $I_{\text {stator.rms }}=\frac{S}{\sqrt{3} E_{s}}$ \\
\hline Field & $I_{F L . r m s}=I_{F S}+\sqrt{\left(I_{F G}+I_{F S I} \sin \phi\right)^{2}+\left(I_{F S I} \cos \phi\right)^{2}}$ \\
\hline Exciter & $I_{\text {exc.ave }}=1.2 \times \frac{I_{F L . r m s}}{12 \times 3}$ \\
\hline
\end{tabular}

For transient thermal analysis, an algorithm is developed for multi-pulse operation, where the number of pulses is an arbitrary input. Due to the negligible influence of temperature rise on circuit parameters, the simulation is based on the original current profiles.

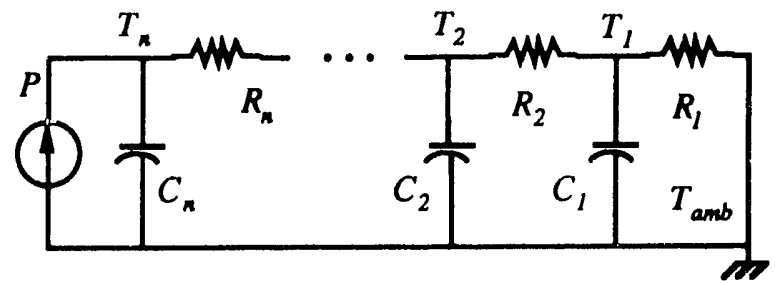

Fig. 4 Basic Thermal Model

\section{CONCLUSION}

Simulation results exhibit satisfactory performance. The following parameters were monitored during the simulations: composite AC input power and energy profiles; generator voltage, current and frequency; electrical and thermal response on each of PF circuits. One of the reference waveforms on the High-Current/Double-Null (HC/DN) scenario[4] is shown in Fig. 5; and Fig. 6-7 show some outputs from this analysis. It has been assumed that MG voltage was reduced to $4 \mathrm{kV}$ during plasma burn instead of $13.8 \mathrm{kV}$ full voltage, and zero voltage margin is allowable during plasma initiation since resistor insertion provides extra boost for the initiation voltage. Fig. 7 illustrates how power supplies are operated bidirectionally. Whenever a circuit is out of operation, a distinct zero-status is imposed on its voltage in simulation. The program is written in FORTRAN and generates files suitable for formatting, graphing or arranging in any fashion.

The resulting computer algorithm has served as a tool of topological optimization for the TPX conceptual design; it is also capable of accommodating all baseline modes of TPX operation.

\section{ACKNOWLEDGMENT}

The authers would like to thank the Engineering Analysis Division of PPPL for support during the course of this work, and also thank U. Christensen for supplying the program for formation of the mutual matrix and C. Kessel for supplying the plasma model.

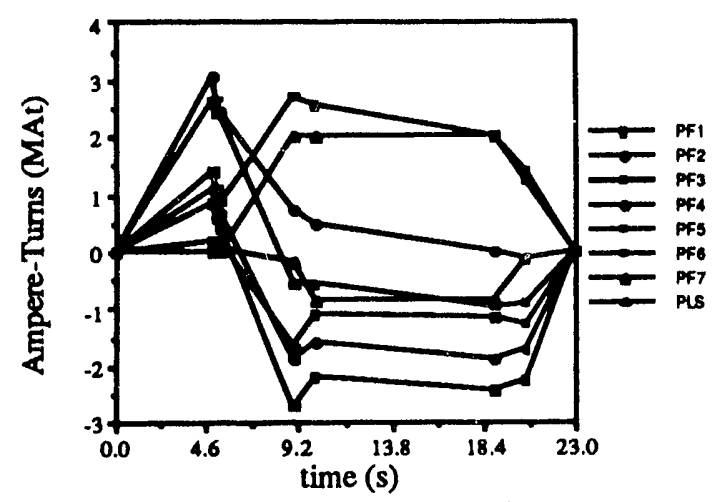

Fig. 5 PF Current Scenario

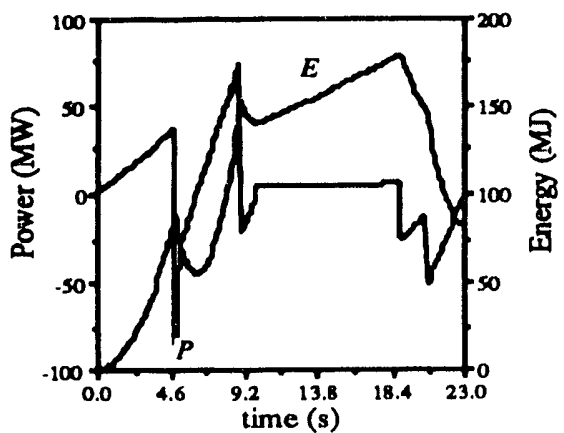

Fig. 6 PF AC Input Power/Energy

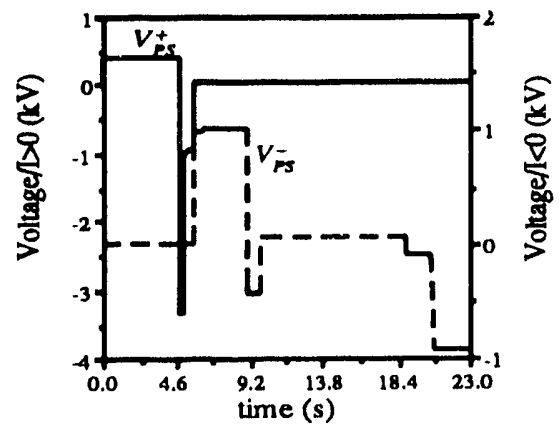

Fig. 7 PF1 Power Supply Voltage

\section{REFERENCES}

[1] E. Lu, "PF Power Systems Simulation," TPX 43930303-PPPL/ELu-01, TPX Power Systems Calculation File 43-2.

[2] C. Neumeyer, G. Bronner, E. Lu, S. Ramakrishnan, M. Jackson, "TPX Power Systems Design Overview," 15th SOFE Conference paper 5-PA-24

[3] C. Neumeyer, "Thermal Models for Simulation Studies,"TPX 43-921014-PPPL/CNeumeyer-01, TPX PS Calculation File 43-1.

[4] J. Schultz, "TPX HC Reference scenario," 1/12/93.

\section{DISCLAIMER}

This report was prepared as an account of work sponsored by an agency of the United States Government. Neither the United States Government nor any agency thereof, nor any of their employees, makes any warranty, express or implied, or assumes any legal liability or responsibility for the accuracy, completeness, or usefulness of any information, apparatus, product, or process disclosed, or represents that its use would not infringe privately owned rights. Reference herein to any specific commercial product, process, or service by trade name, trademark, manufacturer, or otherwise does not necessarily constitute or imply its endorsement, recommendation, or favoring by the United States Government or any agency thereof. The views and opinions of authors expressed herein do not necessarily state or reflect those of the United States Government or any agency thereof. 

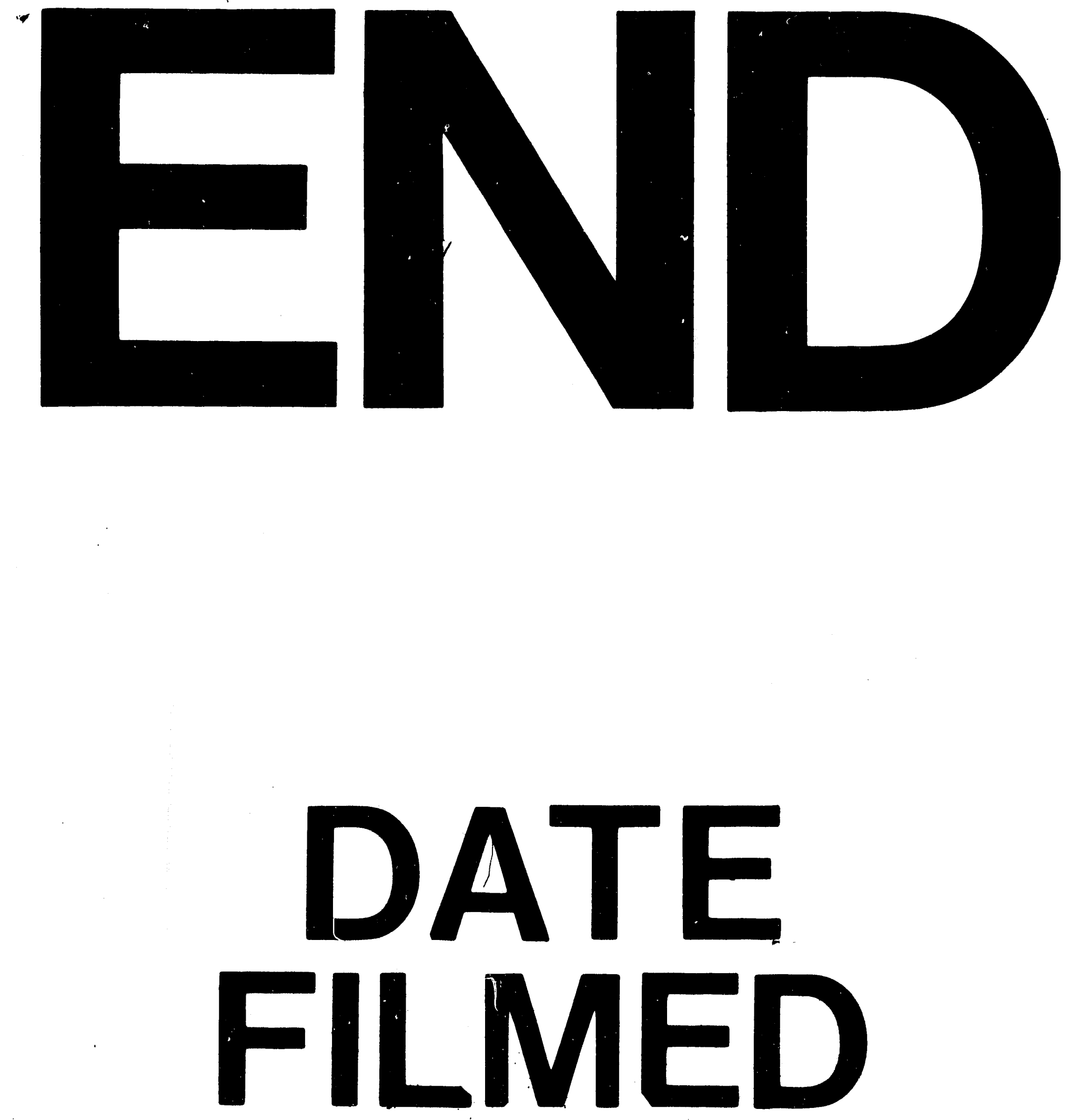

$$
12 / 22 / 93
$$


